\title{
青藏高原西部降水中 $\delta^{18} \mathrm{O}$ 变化特征及其气候意义
}

\author{
余武生 $^{(1)}$, 马耀明 ${ }^{(1)}$, 孙维贞 ${ }^{(2)}$, 王瑜 ${ }^{(2)}$ \\ (1) 中国科学院青藏高原环境变化与地表过程重点实验室, 中国科学院青藏高原研究所, 北京 100085; \\ (2) 冰冻圈科学国家重点实验室, 兰州 730000 \\ E-mail:yuws@itpcas.ac.cn
}

2009-04-08 收稿, 2009-06-22 接受

国家自然科学基金(批准号: 40830638, 40701037)、国家重点基础研究发展计划(编号: 2005CB422004)、中国科学院冰冻圈科学国家重点 实验室开放基金(批准号: SKLCS 08-09)和中国科学院知识创新工程青年人才领域前沿项目资助

摘要 根据青藏高原西部阿里地区狮泉河和改则二站点降水中 $\delta^{18} \mathrm{O}$ 实测值和相关气 象资料, 研究发现, 在一定程度上, 温度能够影响狮泉河和改则二站点降水中 $\delta^{18} \mathrm{O}$ 变 化. 在夏季, 特别是同一降水过程中, 两个站点降水中 $\delta^{18} \mathrm{O}$ 变化趋势非常一致, 且在 季风活跃期, 降水中 $\delta^{18} \mathrm{O}$ 都出现多次明显的低值, 这与西南季风水汽输送密切相关, 而在季风间歇期, 降水中 $\delta^{18} \mathrm{O}$ 仍然表现相对高值, 水汽主要来源于局地水汽的再循 环; 在非季风时段, 降水中 $\delta^{18} \mathrm{O}$ 与温度的正相关性都更为显著, 该研究区域降水的水 汽主要受局地环流和西风环流控制. 另外, 该研究区域的蒸发条件也同样影响降水中 $\delta^{18} \mathrm{O}$ 变化. 通过该区域及其毗邻地区降水中 $\delta^{18} \mathrm{O}$ 空间分布特征的研究, 揭示了 5 月底 或 6 月初始至 8 月底或 9 月初是青藏高原不同水汽来源的一个重要的时间分界线, 而 在空间上, 位于青藏高原北部的西昆仑山与唐古拉山是一条重要的气候分界线.

关键词

青藏高原西部

降水

$\delta^{18} \mathrm{O}$

温度

西南季风
稳定同位素在重建古气候古环境演化的研究中 得到了广泛的应用, 特别是冰芯中稳定同位素记录, 成功地提取了其中蕴含的古气候古环境信息 ${ }^{[1 \sim 5]}$. 而 对冰芯中稳定同位素的研究是基于人们对现代大气 降水中稳定同位素的认识程度 ${ }^{[6 \sim 9]}$.

自 1961 年始, 国际原子能机构(IAEA)和世界气 象组织(WMO)先后在全球建立了 550 个站点, 对全 球降水中稳定同位素进行长期监测(the Global Network of Isotopes in Precipitation, 简称GNIP计划) ${ }^{[6]}$. 然而, 在广阔的青藏高原上站点很少, 故从 1991 年 开始, 中国科学院开始在青藏高原及其周边地区设 立了降水中稳定同位素监测网络(the Tibetan Observation and Research Platform, 简称TORP计划). 2007 年始, 我们启动了一个范围更大的中国河水和降水 稳定同位素观测网络(China Network of Isotopes in
River and Precipitation, 简称CNIRP计划). 前期的研究 结果表明, 青藏高原南部在西南季风降水开始时降水 中 $\delta^{18} \mathrm{O}$ 突然大幅度降低, 由于强烈的西南季风活动, 降 水中 $\delta^{18} \mathrm{O}$ 表现出 “降水量效应” ${ }^{[10 ~ 13]}$, 但是长时间尺度 上, 降水中 $\delta^{18} \mathrm{O}$ 与温度仍然存在一定的正相关关系 ${ }^{[4,5]}$; 在青藏高原中部, 夏季降水中 $\delta^{18} \mathrm{O}$ 也有一定的降低趋 势, 但是相比南部的, 其降低趋势相对较弱 ${ }^{[14]}$; 在青 藏高原北部及其以北地区, 西南季风活动影响甚微, 降 水中 $\delta^{18} \mathrm{O}$ 存在显著的“温度效应”, [12,14 18]. 受西南季风的 影响, 青藏高原降水中 $\delta^{18} \mathrm{O}$ 与温度的关系从南到北出 现了这种渐变过程. 另外, 在青藏高原东部, 夏季降水 中 $\delta^{18} \mathrm{O}$ 同样出现低值, 其受西南季风活动的影响比较 强烈 ${ }^{[19]}$; 在青藏高原西部, 初步的研究也揭示了降 水中 $\delta^{18} \mathrm{O}$ 与温度二者之间存在一定的正相关, 但是夏 季降水中 $\delta^{18} \mathrm{O}$ 受到西南季风的影响也 
很显著 ${ }^{[20]}$.

尽管在青藏高原西部阿里地区有了初步的相关 研究 ${ }^{[20]}$, 但是在该地区, 西南季风向内陆推进的最北 边界问题仍然存在疑问, 而且该地区不同水汽输送 的时间界限也不甚明了. 本文根据在青藏高原西部 阿里地区的改则和狮泉河进行的降水样品收集实验, 分析该地区降水中 $\delta^{18} \mathrm{O}$ 与温度的关系及其变化特征, 揭示该地区的不同水汽来源及其气候意义; 并与周 边地区进行对比分析, 从而揭示西南季风在青藏高 原西部地区能够推进的范围.

\section{1 材料与方法}

\section{1 研究区域概况}

西藏阿里地区位于青藏高原西部, 处于昆仑山、 冈底斯山、喜马拉雅山、念青唐古拉山和唐古拉山等 众多山脉汇聚之地, 改则和狮泉河分别位于阿里地 区东、西部(图 1). 狮泉河地处河谷盆地之中, 气温年 较差比较大, 干燥少雨, 年平均降水量约 $75 \mathrm{~mm}$; 改 则位于南美塘高原湖盆区, 河谷中多湖泊沼泽, 寒冷 干旱、温差大, 年平均降水量为 $190 \mathrm{~mm}$ 左右.

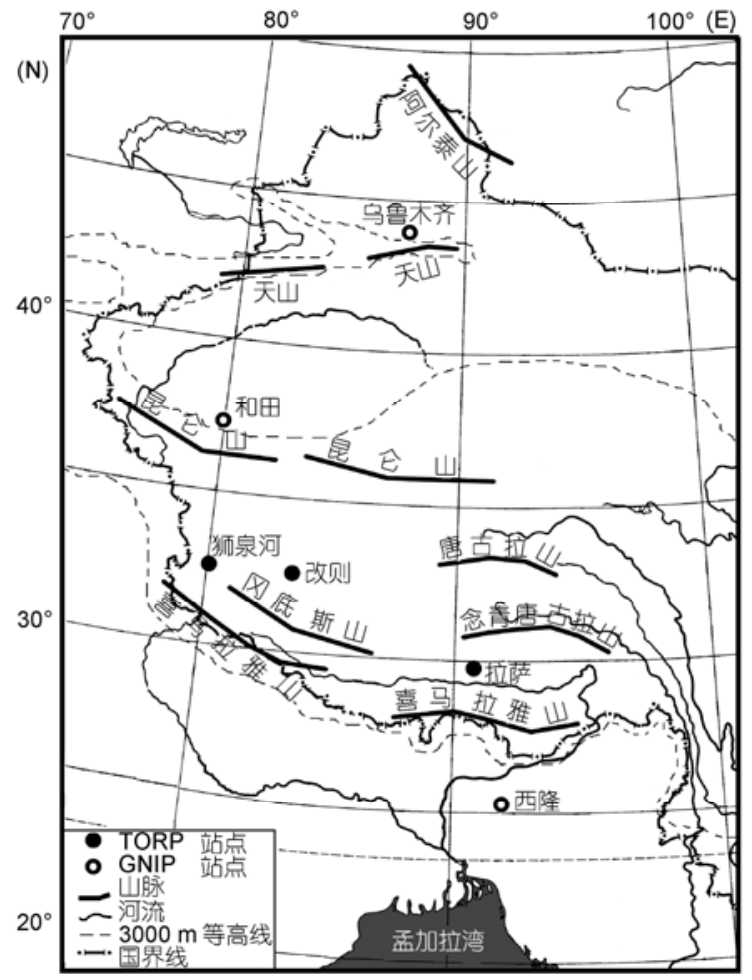

图 1 青藏高原西部阿里地区及其毗邻 地区降水样品收集站点

图中虚线为 $3000 \mathrm{~m}$ 等值线, 以标示青藏高原位置

\section{2 样品收集与分析}

按照气象观测规范要求, 对每次降水过程都实 施取样. 本研究中狮泉河和改则降水样品收集时段 分别为 $1999 \sim 2002$ 年和 $1998 \sim 2003$ 年(表 1). 收集的 降水样品装入干燥洁净的塑料样品瓶里, 并在每个 塑料瓶上按一定顺序编号, 且与降水记录表上编号 一致. 对于固态降水, 则先装入塑料袋里, 扎紧袋口, 在室温下完全融化后, 再装入样品瓶中加以密封. 密 封有降水样品的样品瓶被运回兰州并保存在低温室 内, 样品的测试是在中国科学院冰冻圈科学国家重 点实验室 Delta-Plus 气体质谱仪上进行的, 测得 $\delta^{18} \mathrm{O}$ 的结果为与“标准平均海洋水(VSMOW)”的千分差. 测得 $\delta^{18} \mathrm{O}$ 的精度在 $\pm 0.2 \%$ 之内.

\section{表 1 收集站点及降水样品概况}

\begin{tabular}{ccccc}
\hline 站点 & 和田 & 狮泉河 & 改则 & 拉萨 \\
\hline 纬度 & $37^{\circ} 05^{\prime} \mathrm{N}$ & $32^{\circ} 30^{\prime} \mathrm{N}$ & $32^{\circ} 18^{\prime} \mathrm{N}$ & $29^{\circ} 42^{\prime} \mathrm{N}$ \\
经度 & $79^{\circ} 34^{\prime} \mathrm{E}$ & $80^{\circ} 05^{\prime} \mathrm{E}$ & $84^{\circ} 01^{\prime} \mathrm{E}$ & $91^{\circ} 08^{\prime} \mathrm{E}$ \\
海拔高度 $/ \mathrm{m}$ & 1375 & 4278 & 4430 & 3658 \\
观测期间 & $1988 \sim 1992$ & $1999 \sim 2002$ & $1998 \sim 2003^{\mathrm{a})}$ & $1998 \sim 2003$ \\
年平均 $\delta^{18} \mathrm{O} /(\%)$ & -9.1 & -13.7 & -10.6 & -14.7 \\
降水样品数量 & 47 & 96 & 262 & 593 \\
年平均降水量 $/ \mathrm{mm}$ & 88 & 75 & 190 & 740 \\
年平均温度 $/{ }^{\circ} \mathrm{C}$ & 12.6 & 0.2 & -0.4 & 7.8 \\
\hline
\end{tabular}

a) 1999 年大部分降水样品没有收集

\section{3 数据获取与处理}

在收集降水样品的同时, 还记录了每次降水的 起止时刻、起止地面温度、降水类型以及降水量等多 项气象参数. 为了讨论该研究区域降水中 $\delta^{18} \mathrm{O}$ 的空间 变化, 我们利用了 IAEA/WMO的GNIP计划在青藏高 原北部边缘设立的和田站点(站点编号: 5182800, 数 据获取：http://isohis.iaea.org)以及中国科学院的 TORP计划在青藏高原南部设立的拉萨站点相关稳定 同位素资料. 另外, 引用了NOAA(the National Oceanic \& Atmospheric Administration)公布的相关站点 风速资料(数据获取：http://www.ncdc.noaa.gov/). 狮 泉河、改则和拉萨的月平均大风日数资料引用于文献 [21]，和田的月平均大风日数及年平均降水量资料由 中国国家气象信息中心提供. 我们还利用了NCEP/ NCAR (National Centers for Environmental Prediction/ US National Center for Atmospheric Research)所提供 
的 2002 年月平均风向、风速以及空气比湿等重分 析资料, 用于计算青藏高原及其毗邻地区 2002 年冬、 夏季 $500 \mathrm{hPa}$ 风场和 $500 \sim 300 \mathrm{hPa}$ 水汽通量场. 该数 据集的空间精度为 $2.5^{\circ} \times 2.5^{\circ}$ (经度 $\times$ 纬度)(数据获取： http://www.cdc.noaa.gov/data/grid-ded/data.ncep.reanalysis. html). 水汽通量场的计算方法如下:

鉴于青藏高原及其毗邻地区 $300 \mathrm{hPa}$ 以上大气水 汽含量很低, 我们只计算近地表气压到 $300 \mathrm{hPa}$ 之间 的水汽通量, 根据Rasmusson ${ }^{[22]}$ 方程, 则某单位气柱 整层大气水汽输送通量矢量 $Q=\left(Q_{\lambda}, Q_{\varphi}\right)$ 可得:

$$
\vec{Q}=\frac{1}{g} \int_{300}^{p_{0}} \vec{V} \cdot q \mathrm{~d} p=\frac{1}{g} \int_{300}^{p_{0}}(u, v) \cdot q \mathrm{~d} p .
$$

因此, 分别可得在经向和纬向水汽输送通量 $Q_{\lambda}$ 与 $Q_{\varphi}$ 的计算公式如下:

$$
\begin{aligned}
& Q_{\lambda}=\frac{1}{g} \int_{300}^{p_{0}} u q \mathrm{~d} p, \\
& Q_{\varphi}=\frac{1}{g} \int_{300}^{p_{0}} v q \mathrm{~d} p,
\end{aligned}
$$

式中, $\vec{V}$ 为该单位气柱各层大气的风速矢量, $u$ 和 $v$ 分别为东西风(经向)和南北风(纬向), $q$ 是该单位气柱 各层大气的比湿, $P_{0}$ 是青藏高原平均地面气压, 这里 取 $P_{0}=500 \mathrm{hPa}$. 这样, 利用式(1) (3), 并由 NCEP/ NCAR 格点资料可以计算出青藏高原及其毗邻地区 冬、夏季水汽输送通量. 为了简化计算, 然后对每个 对应的经向和纬向水汽输送通量矢量进行平方根运 算, 可得到水汽通量场, 其方向与风向相同:

$$
Q=Q_{\lambda} i_{\lambda}+Q_{\varphi} i_{\varphi} .
$$

\section{2 结果与讨论}

\section{1 降水中 $\delta^{18} \mathrm{O}$ 与温度变化}

与前期的初步研究 ${ }^{[20]}$ 比较, 本研究补充了已有 的狮泉河 2000 年数据, 并增加了改则 2002 年 9 月 5 日 2003 年 9 月 24 日时间段数据. 从狮泉河和改则二 站点历次降水中 $\delta^{18} \mathrm{O}$ 和降水温度的散点分布图上看, 二者之间存在一定的正相关关系, 回归方程分别为: $\delta^{18} \mathrm{O}=0.33 T-16.04$ 和 $\delta^{18} \mathrm{O}=0.24 T-12.57$, 相关系 数 $r$ 分别为 0.31 和 0.20 , 都能通过 0.01 的信度检验(图 2). 不过, 与狮泉河的相比, 改则降水中 $\delta^{18} \mathrm{O}$ 和降水 时气温之间的相关性相对较弱.

图 3 揭示了狮泉河和改则降水中月平均 $\delta^{18} \mathrm{O}$ 与 月平均降水温度的关系(由于有些月份只有一次降水, 加权平均会因为权重分配过于不均而产生更大的误 差, 故只取算数平均), 研究发现, 该二站点降水中月平 均 $\delta^{18} \mathrm{O}$ 与月平均降水温度二者之间相关性更为显著, 其 回归方程分别为: $\delta^{18} \mathrm{O}=0.37 \bar{T}-14.54$ 和 $\delta^{18} \mathrm{O}=$

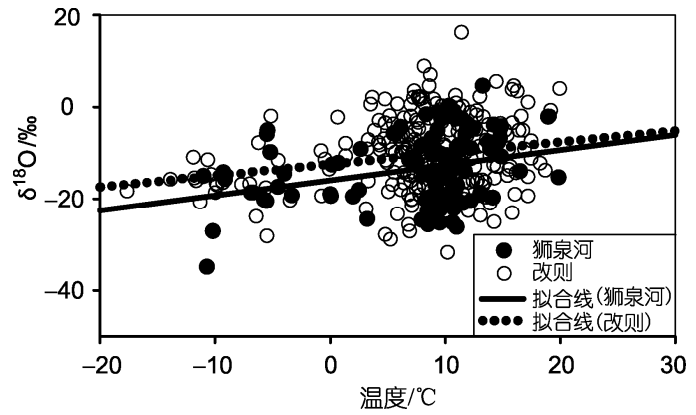

图 2 狮泉河与改则历次降水中 $\delta^{18} \mathrm{O}$ 和 降水时气温的散点分布图

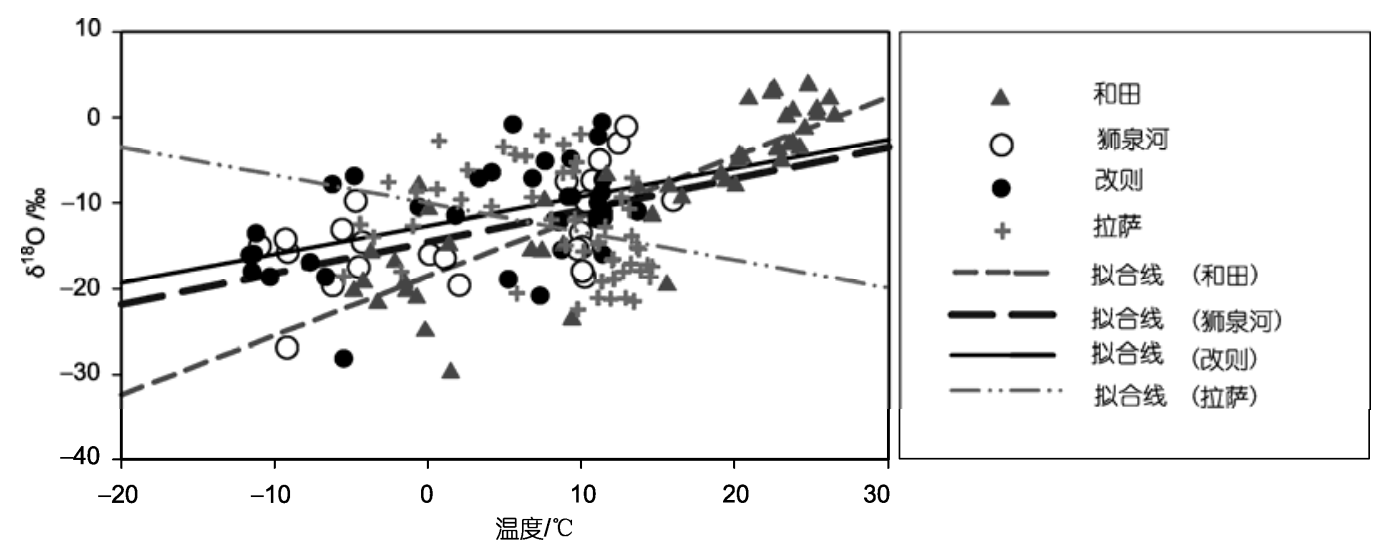

图 34 站点降水中月平均 $\delta^{18} \mathrm{O}$ 与月平均降水温度的关系 
$0.33 \bar{T}-12.62$, 相关系数分别达到 0.55 和 0.47 , 在 0.01 的置信区间上都很显著, 由此可见, 在一定程度 上, 青藏高原西部降水中 $\delta^{18} \mathrm{O}$ 受温度变化影响. 同样 的, 在月平均尺度上, 改则降水中月平均 $\delta^{18} \mathrm{O}$ 与月平 均降水温度之间的正相关性还是要弱于狮泉河的.

另外, 我们引用了 GNIP 的和田站点以及 TORP 的拉萨站点降水中 $\delta^{18} \mathrm{O}$ 资料, 发现在青藏高原南部的 拉萨, 降水中月平均 $\delta^{18} \mathrm{O}$ 与月平均降水温度之间不存 在正相关关系, 甚至存在一定的“负相关”(图 3). 而在 青藏高原北部边缘的和田, 降水中 $\delta^{18} \mathrm{O}$ 与温度之间 存在显著的线性关系, 相关系数高达 0.85 . 而且很容 易看出, 从南到北, 随着纬度的升高, 降水中 $\delta^{18} \mathrm{O}$ 与 温度之间的正相关性逐渐显著, 而且在整体上, 对应 的斜率也有一个随着纬度的升高逐渐增大的趋势: 拉萨的为负值 $(-0.33)$, 改则和狮泉河的在 0.3 左右, 和田的为 0.70 .

\section{2 降水中 $\delta^{18} \mathrm{O}$ 揭示的水汽来源}

不同的水汽来源对降水中 $\delta^{18} \mathrm{O}$ 变化具有显著的 影响 ${ }^{[10]}$, 因此, 通过降水中 $\delta^{18} \mathrm{O}$, 特别是其季节变化 特征的分析, 可以反过来揭示当地的水汽来源. 青藏 高原西部阿里地区狮泉河和改则降水中 $\delta^{18} \mathrm{O}$ 都表现 出很大的波动(图 4). 狮泉河降水中 $\delta^{18} \mathrm{O}$ 波动的幅度 在-33.9\% 4.5\% 之间, 其平均值为 $-13.7 \%$; 改则降 水中 $\delta^{18} \mathrm{O}$ 波动的幅度在-31.7\%o 16.1\%。之间, 其平
均值为-10.6\% . 与狮泉河的相比, 改则降水中 $\delta^{18} \mathrm{O}$ 平均值要高得多, 其波动范围更大, 波动的频率也更 高(图 4(b)). 该二站点降水中 $\delta^{18} \mathrm{O}$ 还有一个共同的特 点, 就是在 $7 \sim 8$ 月降水中 $\delta^{18} \mathrm{O}$ 多次出现相对低值, 而 且这种突然降低的事件几乎在每个年份内都有所表 现. 这种降水中 $\delta^{18} \mathrm{O}$ 出现突然降低与西南季风的入侵 有着密切关系. 特别是在改则站点, 降水中 $\delta^{18} \mathrm{O}$ 这种 突然降低的事件表现得比较频繁, 甚至在 6 月底也都 有所出现, 如图 4(b)所示. 这说明, 西南季风对改则 地区的侵扰要比对狮泉河的相对强烈, 而且来得更 早. 这也导致了改则降水中 $\delta^{18} \mathrm{O}$ 与气温的关系没有狮 泉河的显著. 而且从图 4 还可以看出, 在夏季, 降水 量大的降水事件都几乎对应降水中 $\delta^{18} \mathrm{O}$ 的相对低值 时刻. 这种降水中 $\delta^{18} \mathrm{O}$ 表现出突然降低的特征与受西 南季风影响的拉萨降水中 $\delta^{18} \mathrm{O}$ 的变化特征有一定的 相似之处 ${ }^{[12,14]}$, 这也进一步证实了, 与拉萨一样, 西 南季风的水汽输送对青藏高原西部地区降水有较大 的贡献, 即西南季风降水中较低的 $\delta^{18} \mathrm{O}$ 导致该区域夏 季降水中 $\delta^{18} \mathrm{O}$ 的出现多次相对低值, 使得狮泉河和改 则降水中 $\delta^{18} \mathrm{O}$ 和降水时气温之间的关系 没有位于非季风区的青藏高原北部边缘的和田站点 的显著.

从图 4 还可以看出, 在整个夏季降水期间, 除了 在季风活跃期狮泉河和改则降水中 $\delta^{18} \mathrm{O}$ 出现低值事 件外, 而其他降水时段中 $\delta^{18} \mathrm{O}$ 仍然是相对高值, 这对
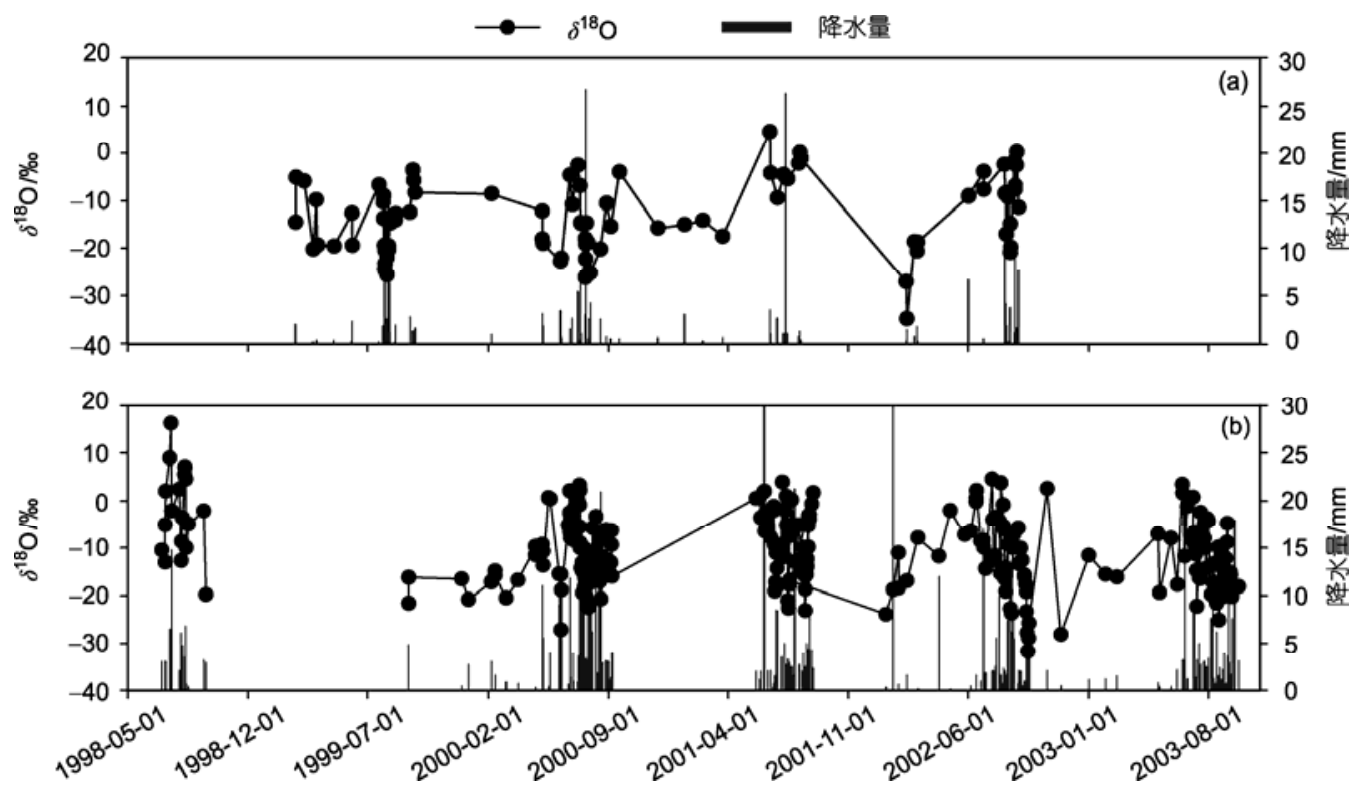

图 4 狮泉河(a)和改则(b)降水中 $\delta^{18} \mathrm{O}$ 的日变化 点-直线为 $\delta^{18} \mathrm{O}$, 下方柱状图为日降水量 
应于西南季风间歇期，在此间歇期，该地区的水汽来 源主要是局地水汽的再循环. 由于狮泉河和改则地 处干旱区, 这种局地水汽中 $\delta^{18} \mathrm{O}$ 值相对较高, 该水汽 的再循环引起的降水中 $\delta^{18} \mathrm{O}$ 值也就偏高, 且对应的 降水量相对较低. 由此可见, 在青藏高原西部阿里地 区夏季降水的水汽来源主要受西南季风和局地环流 的共同作用，而西南季风稍占主导地位. 与狮泉河相 比, 改则夏季降水受西南季风更为强烈, 使得改则夏 季西南季风降水所占比例要高于狮泉河的.

若仅考虑狮泉河和改则二站点同一降水过程, 发现除了 2000 年 2 月 6 日改则降水中 $\delta^{18} \mathrm{O}$ 要低于狮 泉河的外, 该二站点降水中 $\delta^{18} \mathrm{O}$ 的波动趋势几乎完 全一致(图 5), 线性拟和二者之间的关系, 可得回归 方程为 $y=0.62 x-3.28$, 相关系数高达 0.73 (不包括 2000 年 2 月 6 日降水); 而且该二站点降水中 $\delta^{18} \mathrm{O}$ 都 是在 7,8 月出现明显的低值事件. 进一步分析发现, 该二站点的同一降水事件，除了 2000 年 2 月 6 日的, 几乎都发生在夏季, 而恰恰是 2000 年 2 月 6 日的降 水事件其降水中 $\delta^{18} \mathrm{O}$ 不在同一变化趋势上. 可见, 至 少在同一降水事件发生时段, 狮泉河和改则有着相 同的水汽来源, 特别是在夏季, 尤其如此.

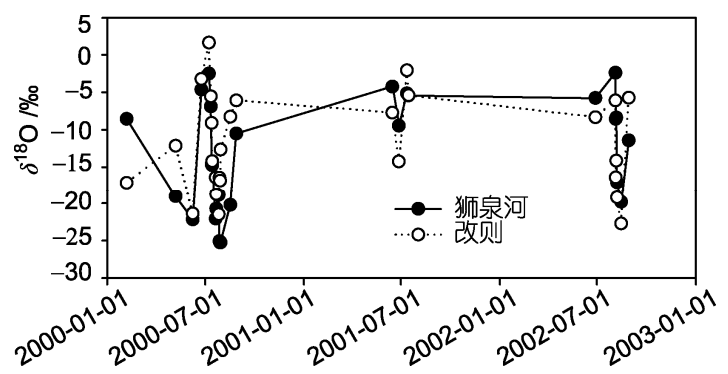

图 5 狮泉河和改则同一降水过程降水中 $\delta^{18} \mathrm{O}$ 变化特征 实心圆-直线代表狮泉河, 空心圆-虚线代表改则

那么, 在冬季, 该二站点降水的水汽来源又是怎 样的呢? 下面我们将对非季风期降水中 $\delta^{18} \mathrm{O}$ 变化及 其与温度的关系进行阐述. 从图 6(d)可以看出, 在青 藏高原南部的拉萨, 10 月 翌年 5 月, 即西南季风爆 发前和撤退后, 水汽主要来源于局地环流和西风携 带的水汽输送, 降水中 $\delta^{18} \mathrm{O}$ 与温度的变化趋势比较一 致 ${ }^{[10,14]}$; 西南季风爆发后, 降水中 $\delta^{18} \mathrm{O}$ 出现明显的低 值, 其变化趋势与温度相反 ${ }^{[14]}$, 降水中 $\delta^{18} \mathrm{O}$ 受西南季 风的“降水量效应”影响 $[10]$ 。在青藏高原西部的
改则、狮泉河，在非季风期(10 月 翌年 6 月), 降水中 $\delta^{18} \mathrm{O}$ 与温度的变化趋势同样比较一致, 水汽来源主要 受局地环流和西风环流控制 ${ }^{[23]}$; 进入雨季, 随着强 烈的西南季风推进到该区域, 降水中 $\delta^{18} \mathrm{O}$ 出现低值, 其变化趋势与温度的相反, 但西南季风推进到该区 域时, 其强度已大为减弱, 因此, 该区域夏季降水中 $\delta^{18} \mathrm{O}$ 出现低值的频次要低于拉萨的, 而且其降低的程 度相对更弱. 随着西南季风的进一步向北推进, 由于 西南季风的明显减弱, 而且受到西昆仑山脉的强力阻 挡, 越过西昆仑山后, 西南季风的影响更为减弱至微 乎其微, 使得位于西昆仑山北部的和田站点夏季降水 中 $\delta^{18} \mathrm{O}$ 仍然表现为高值, 且与温度的变化趋势非常一 致, 该地区水汽常年受局地环流和西风环流影响, 特 别是该地区夏季局地水汽的再循环对当地降水具有很 大的贡献, 从而使得降水中 $\delta^{18} \mathrm{O}$ 出现高值, 并与温度 呈正相关 ${ }^{[10]}$. 这说明, 由西而东横亘在青藏高原北部 的高大的西昆仑山脉是一条重要的气候分界线. 更多 的证据说明, 唐古拉山是青藏高原中部一个重要的分 界线 ${ }^{[12,14,19,23 \sim 25]}$. 因此, 位于 $35^{\circ} \mathrm{N}$ 一线附近的西昆仑 山与唐古拉山, 形成整个青藏高原面上乃至整个中国 西部一条重要的气候分界线, 而 $32-33^{\circ} \mathrm{N}$ 区域是季风 区和非季风区的过渡地带, 我们的研究站点一狮泉 河和改则就落在这个过渡区中. 因此, 青藏高原西部 地区降水中 $\delta^{18} \mathrm{O}$ 受到西南季风、局地环流及西风环流 的共同作用.

对图 6 中降水中 $\delta^{18} \mathrm{O}$ 与温度变化趋势深入分析 发现, 从南到北, 西南季风爆发前和撤退后, 即非季 风时段, 拉萨、改则和狮泉河降水中 $\delta^{18} \mathrm{O}$ 与温度变化 趋势都非常相似. 于是分别计算各站点非季风时段 降水中月平均 $\delta^{18} \mathrm{O}$ 与月平均温度之间的相关性, 发 现各自的相关性都要远远显著于它们全年尺度上降 水中 $\delta^{18} \mathrm{O}$ 与温度的相关性(方程(3) (5). 而西南季风 活动期间, 受西南季风影响的区域降水中 $\delta^{18} \mathrm{O}$ 都出 现低值, 而且从南到北, 其降低的程度有一个逐渐减 弱的趋势, 也即, 降水中 $\delta^{18} \mathrm{O}$ 与温度的变化趋势越来 越相似, 直到北部受季风影响甚微的和田, 降水中 $\delta^{18} \mathrm{O}$ 与温度的变化趋势完全一致, 而在季风爆发前, 二者之间的相关性并没有得到提高, 相关系数为 0.80 , 与全年的相比相差无几. 这说明在夏季, 强烈的西南 季风活动削弱了降水中 $\delta^{18} \mathrm{O}$ 与温度之间的相关性. 
- 温度
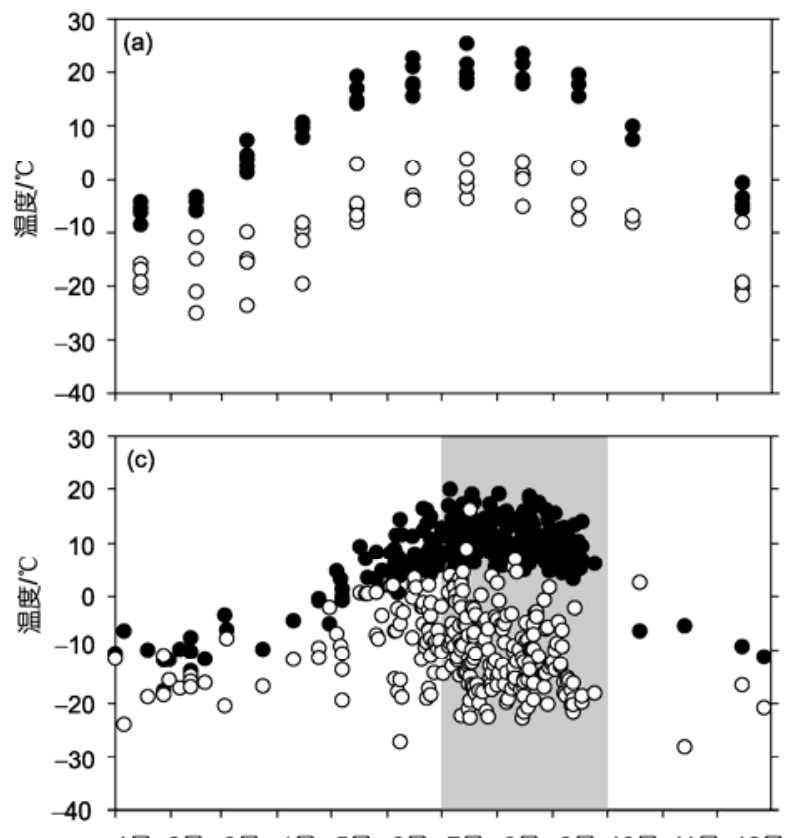

1月 2 月 3 月 4 月 5 月 6 月 7 月 8 月 9 月 10 月 11 月 12 月 $\circ \delta^{18} \mathrm{O}$
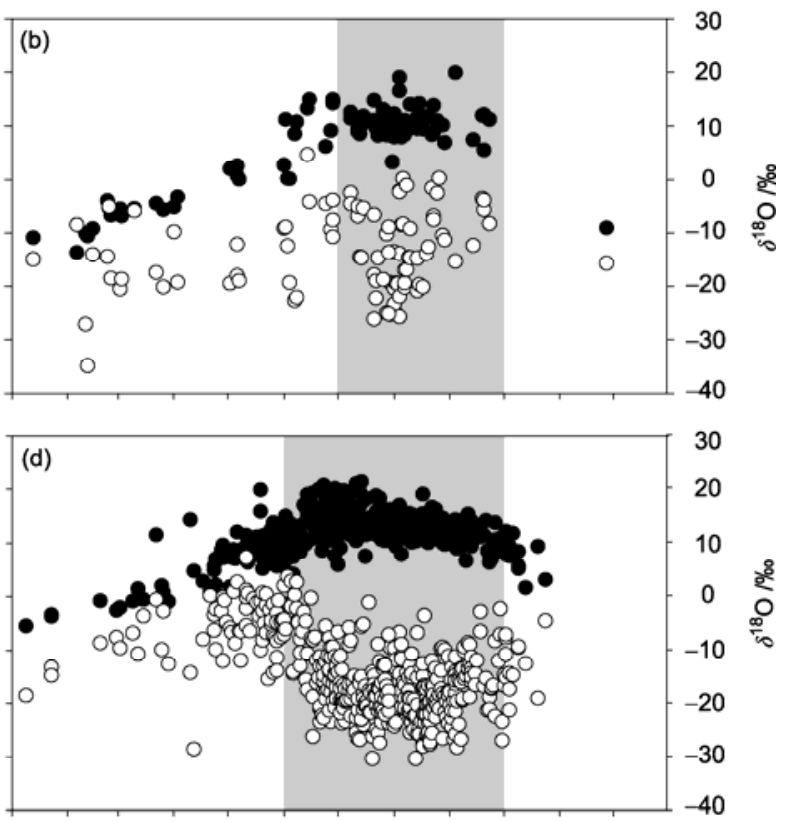

1月 2 月 3 月 4 月 5 月 6 月 7 月 8 月 9 月 10 月 11月 12 月

图 6 青藏高原西部及其毗邻地区降水中 $\delta^{18} \mathrm{O}$ 季节变化

（a）和田; (b) 狮泉河; (c) 改则; (d) 拉萨. 阴影区域为季风时段

狮泉河:

$\delta^{18} \mathrm{O}=0.50 T-13.58(r=0.68, n=17, P<0.01)$.

改则:

$\delta^{18} \mathrm{O}=0.62 T-10.36(r=0.62, n=18, P<0.01) .(4)$ 拉萨:

$\delta^{18} \mathrm{O}=0.36 T-10.74(r=0.34, n=27, P<0.01) .(5)$

另外，我们利用NCAR/NCEP气象格点资料对阿 里地区狮泉河和改则水汽输送路径分别进行追踪分 析 ${ }^{[15,26]}$, 结果发现, 两站点水汽来源情况比较相似, 季风爆发前(如: 2002 年 6 月 2 日)以局地水汽的再循 环为主, 降水中 $\delta^{18} \mathrm{O}$ 表现为相对高值; 季风活跃期 (如: 2002 年 8 月 15 日), 来自阿拉伯海和孟加拉湾的 海洋性水汽的输送直接影响研究区域的降水, 降水 中 $\delta^{18} \mathrm{O}$ 表现为明显的低值; 而在季风间歇期(如: 2002 年 7 月 13 日), 降水的水汽来源以局地水汽的再循环 为主, 改则降水中 $\delta^{18} \mathrm{O}$ 表现为正值 (图略). 显然, 水 汽追踪的结果与上述我们的分析结果完全吻合.

因此，根据上述青藏高原西部的狮泉河和改则 以及南部的拉萨降水中 $\delta^{18} \mathrm{O}$ 的时空变化特征, 我们 不难发现, 5 月底或 6 月份初始至 8 月底或 9 月初是 一个重要的时间分界线, 而位于 $35^{\circ} \mathrm{N}$ 一线附近的西 昆仑山和唐古拉山是一个重要的空间分界线.
全球降水中 $\delta^{18} \mathrm{O}$ 分布有一个显著的特点, 即随着 纬度的升高, 降水中 $\delta^{18} \mathrm{O}$ 逐渐降低 ${ }^{[27]}$, 如: 印度西隆 降水中 $\delta^{18} \mathrm{O}$ 年平均值为 $-4.59 \%$ (观测期间：1969.1 1978.10), 和田的为 $-9.14 \%$, 乌鲁木齐的为 $-12.43 \%$ o(观测期间: 1986.2 2002.12), 降水中 $\delta^{18} \mathrm{O}$ 呈 现所谓的“大陆性效应”(图 7(a)). 但是由于青藏高原 的存在, 其独特的地形及诸多高䇯山脉的屏障作用, 迫使来自印度洋的海洋性水汽抬升到高空, 由于高 空温度很低, 水汽得以充分冷凝, 同位素分馏程度很

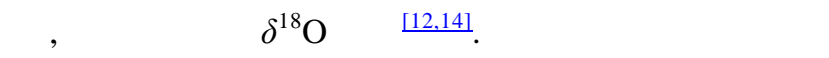
古拉山等高大山脉的南部, 西南季风的对流活动非 常剧烈, 使得降水中 $\delta^{18} \mathrm{O}$ 出现低值, 如同图 7(a)中阴 影部分所示, 在高原面上, 降水中 $\delta^{18} \mathrm{O}$ 的“大陆性效 应”已不复存在, 从而打破了降水中 $\delta^{18} \mathrm{O}$ 这种全球性 分布格局. 可见, 在青藏高原上, 这种特殊的降水中 $\delta^{18} \mathrm{O}$ 分布特征与青藏高原本身独特的地形地势, 特殊 的环流系统等有着密切关系.

既然夏季由于西南季风的影响, 于是我们剔除 季风期再次分析从沿海的西隆到内陆的乌鲁木齐降 水中 $\delta^{18} \mathrm{O}$ 的空间变化特征. 为了完全排除西南季风 的影响, 我们只统计各个站点 1 4 月和 11 12 月期 


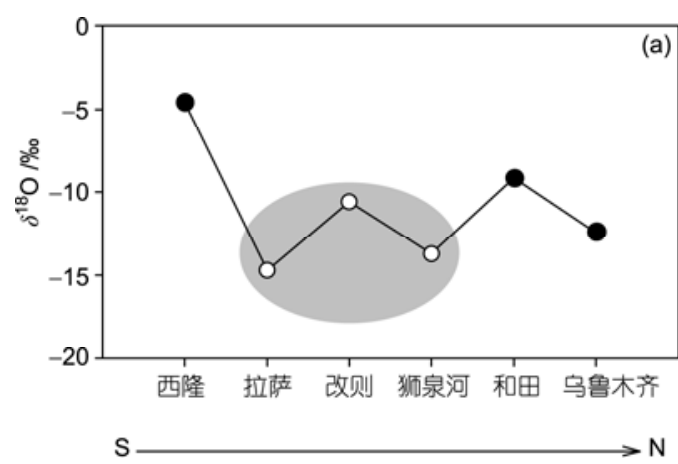

图 7 从沿海到内陆, 全年(a)及非季风时段(b)降水中 $\delta^{18} \mathrm{O}$ 的空间变化
间的样本, 结果发现, 与全球降水中 $\delta^{18} \mathrm{O}$ 空间分布格 局完全一致: 从西隆到乌鲁木齐, 随着纬度的升高, 降水中 $\delta^{18} \mathrm{O}$ 逐渐降低(图 7(b)). 这也再次证实了在青 藏高原上夏季降水由于受到强烈的西南季风影响, 导致降水中年平均 $\delta^{18} \mathrm{O}$ 出现相对低值区域. 而且从 图 7(b)中, 还可以看出, 从沿海的西隆到西昆仑山之 前, 降水中 $\delta^{18} \mathrm{O}$ 迅速降低, 越过西昆仑山后, 降水中 $\delta^{18} \mathrm{O}$ 降低的幅度显著减小.

从空间分布看(图 7(a)), 改则和狮泉河降水中 $\delta^{18} \mathrm{O}$ 年平均值都要高于拉萨的, 这主要归因于夏季西 南季风向青藏高原西北内陆推进后, 其强度逐渐减 弱有关. 另外, 改则和狮泉河二站点都位于干旱区, 其强烈的地表蒸发对降水中 $\delta^{18} \mathrm{O}$ 也产生不可忽略的 影响. 从图 8 可以看出, 改则和狮泉河的月平均风速 都几乎高于拉萨的, 而该二站点的月平均大风日数 更是远远高于拉萨的 ${ }^{[21]}$. 这种局地气候特征使得地 表水汽蒸发以及雨滴在降落的过程中的二次蒸发都 更为强烈, 从而导致该二站点 $\delta^{18} \mathrm{O}$ 年平均值都要高于 拉萨的. 同是在青藏高原西部阿里地区, 改则降水中 $\delta^{18} \mathrm{O}$ 年平均值要高于狮泉河的, 这与改则当地的特殊 的局地气候环境条件有关. 改则月平均大风日

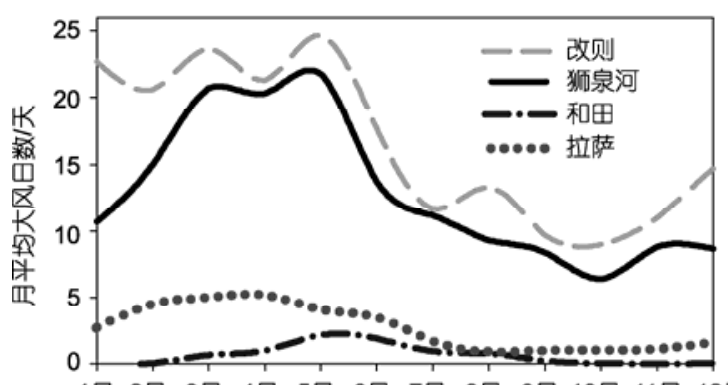

1月 2月 3月 4月 5月 6月 7月 8月 9月 10月 11月 12月

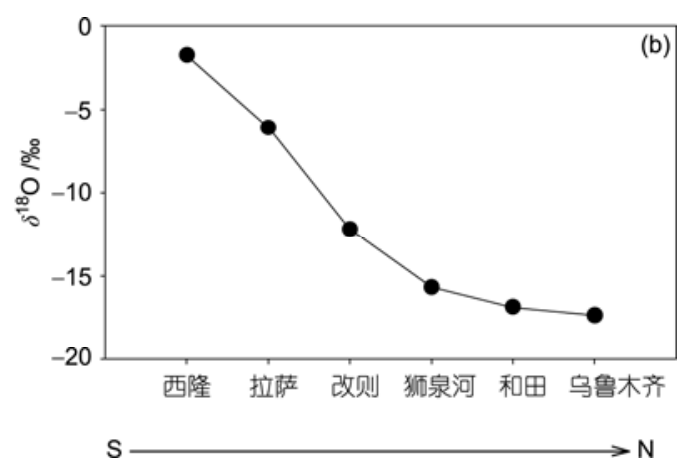

数多于狮泉河, 且其月平均风速要远远高于狮泉河 (图 8); 而改则、狮泉河年平均蒸发潜热通量分别为 15.4 和 $2.9 \mathrm{~W} / \mathrm{m}^{2}[28]$, 显然改则的要远远高于狮泉河 的; 另外, 根据改则和狮泉河二气象台站资料, 改则 的年蒸发量高达 $2429.2 \mathrm{~mm}$, 而狮泉河的年蒸发量为 $2089.2 \mathrm{~mm}$, 相对较小. 因此, 改则的当地蒸发更为 强烈, 使得改则的降水中 $\delta^{18} \mathrm{O}$ 年平均值要高于狮泉河 的.

为进一步论证上述观点, 我们利用 NCEP/NCAR 气象格点资料, 分别计算了青藏高原及其毗邻地区 $1998 \sim 2003$ 年每年度的冬季(1 月)、夏季(7 月) $500 \mathrm{hPa}$ 高度的风场和 $500 \sim 300 \mathrm{hPa}$ 的水汽通量场. 图 9 为 2002 年冬季( 1 月)、夏季(7 月)的结果. 显然, 在冬季, 高的水汽通量出现在海洋, 而整个研究区域都受局 地环流和西风环流控制, 水汽通量都很低, 降水很少, 使得四站点降水中 $\delta^{18} \mathrm{O}$ 与温度的变化趋势都很相似, 即使是在青藏高原南部的拉萨, 也是如此. 在夏季, 可以清楚的看出, 和田站点的水汽来源主要受局地环 流和西风环流控制, 水汽通量低, 因而该站点夏季降水 中 $\delta^{18} \mathrm{O}$ 与温度之间仍然表现出很好的正相关. 而青藏高 原南部直到中部和西部主要都受到西南季风的影响:

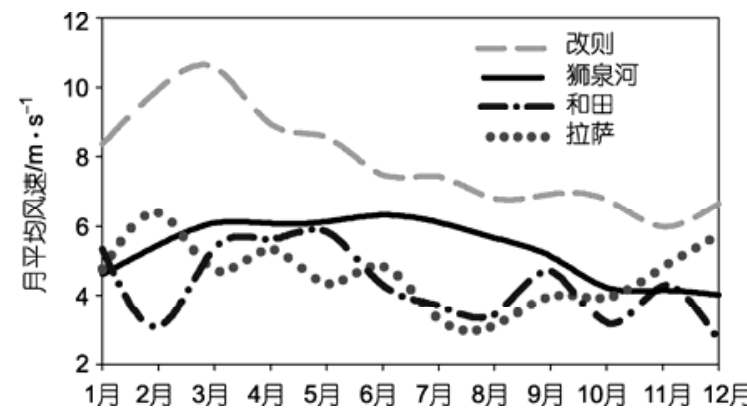

图 84 站点月平均大风日数与月平均风速 

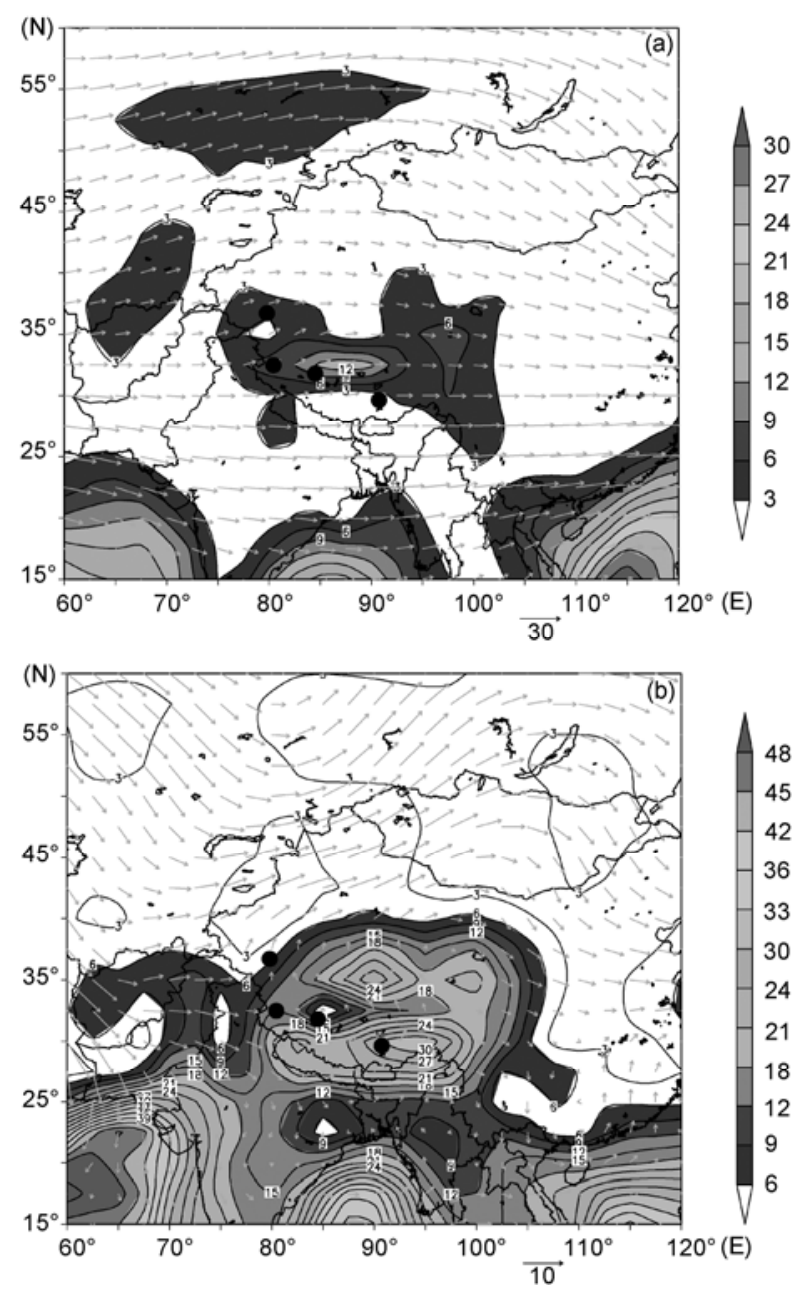

图 9 青藏高原及其毗邻地区 2002 年 1 月(a)、7 月(b) 500 hPa 风场和 500 300 hPa 水汽通量场

其方向与风向一致, 单位为: $\mathrm{g} /(\mathrm{cm} \cdot \mathrm{hPa} \cdot \mathrm{s})$, 右下角箭头 表示风速, 单位为: $\mathrm{m} / \mathrm{s}$

西南季风携带的水汽从阿拉伯海和孟加拉湾向内陆 输送, 越过喜马拉雅山脉后, 在青藏高原上水汽通量 出现一个相对高值区, 降水增多. 西南季风的推进, 导致了拉萨、改则和狮泉河等站点夏季降水中 $\delta^{18} \mathrm{O}$ 出 现低值, 从而削弱了降水中 $\delta^{18} \mathrm{O}$ 与温度之间的正相关 关系. 另外，在季风间歇期，局地环流的水汽对拉萨 乃至阿里地区的水汽来源也有一定的贡献. 其他年份 冬、夏季的结果与 2002 年的相似(图略).

\section{3 结论}

通过对青藏高原西部阿里地区狮泉河和改则降 水中 $\delta^{18} \mathrm{O}$ 变化特征及其与温度的关系分析, 可以得 出以下结论:

在狮泉河和改则历次降水中 $\delta^{18} \mathrm{O}$ 与温度之间都 存在一定的正相关, 尤其是在月平均尺度上, 二者之 间的相关性更为显著. 这表明, 在长时间尺度上, 温 度是影响狮泉河和改则降水中 $\delta^{18} \mathrm{O}$ 变化的因子之一. 而在夏季, 特别是同一降水过程中, 该二站点降水中 $\delta^{18} \mathrm{O}$ 变化趋势完全一致, 且在季风活跃期, 该二站点 降水中 $\delta^{18} \mathrm{O}$ 都出现低值, 这与夏季西南季风水汽输 送密切相关, 而在季风间歇期, 降水中 $\delta^{18} \mathrm{O}$ 仍然表现 相对高值, 水汽主要来源于局地水汽的再循环与西风 环流. 可见, 不同的环流系统, 特别是西南季风是影 响该二站点夏季降水中 $\delta^{18} \mathrm{O}$ 变化的另一个关键因子.

由于改则月平均风速远高于狮泉河, 而且蒸发 潜热通量要远高于狮泉河, 加之强烈的大风天气, 使 得地表水汽蒸发以及雨滴在降落的过程中的二次蒸 发都更为强烈. 因此, 与狮泉河相比, 改则降水中 $\delta^{18} \mathrm{O}$ 年平均值相对较高. 因而, 在青藏高原西部阿里 地区, 影响降水中 $\delta^{18} \mathrm{O}$ 变化的因子有温度、水汽来源 和蒸发条件等.

青藏高原西部阿里地区降水中 $\delta^{18} \mathrm{O}$ 季节变化特 征, 揭示了该区域夏季西南季风和局地环流共同作 用，且西南季风携带的水汽输送稍占主导地位; 而在 西南季风爆发前和撤退后, 该区域水汽主要受局地 环流和西风环流控制. 通过该区域及其毗邻地区降 水中 $\delta^{18} \mathrm{O}$ 空间分布特征的研究, 揭示了 5 月底或 6 月初始至 8 月底或 9 月初是青藏高原不同水汽来源的 一个重要的时间分界线. 而青藏高原西部阿里地区 北部的西昆仑山, 由于对西南季风的进一步阻挡屏 蔽, 使得青藏高原北部边缘的和田降水中 $\delta^{18} \mathrm{O}$ 与温 度的变化趋势几乎同步, 表现为典型的“夏高冬低” 特征, 这说明位于 $35^{\circ} \mathrm{N}$ 一线附近的西昆仑山与唐古 拉山, 在空间上, 是青藏高原一条重要的气候分界线. 这对于西南季风在青藏高原面上能够推进的范围有 了新的认识, 具有重要的气候意义. 


\section{参考文献}

1 Johnsen S J, Dansgaard W, Clausen H B, et al. Oxygen isotope profiles through the Antarctic and Greenland ice sheets. Nature, 1972, 235: 429-434[doi]

2 Lorius C, Jouzel J, Ritz C, et al. A 150,000-year climatic record from Antarctic ice. Nature, 1985, 316: 591-596[doi]

3 Dansgaard W, Johnsen S J, Clausen H B, et al. Evidence for general instability of past climate from a 250-kyr ice-core record. Nature, 1993, 364: 218-220[doi]

4 Thompson L G, Yao T D, Mosley-Thompson E, et al. A high-resolution millennial record of the South Asian Monsoon from Himalayan ice cores. Science, 2000, 289: 1916-1919 [doi]

5 Yao T D, Thompson L G, Mosley-Thompson E, et al. Climatological significance of $\delta^{18} \mathrm{O}$ in north Tibetan ice cores. J Geophys Res,

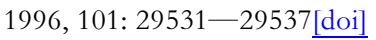

6 Dansgaard W. Stable isotopes in precipitation. Tellus, 1964, 16: 436-468

7 Rozanski K, Araguás-Araguás L, Gonfiantini R. Relation between long-term trends of oxygen-18 isotope composition of precipitation and climate. Science, 1992, 258: 981-985 $\underline{\text { [doi] }}$

8 Jouzel J, Merlivat, L. Deuterium and oxygen-18 in precipitation: Modeling of the isotope effects during snow formation. J Geophys Res, 1984, 89: 11749-11757[doi]

9 Jouzel J, Russell G L, Suozzo R J, et al. Simulations of $\mathrm{HDO}$ and $\mathrm{H}_{2}{ }^{18} \mathrm{O}$ atmospheric cycles using the NASA/GISS general circulation model: The seasonal cycle for present-day conditions. J Geophys Res, 1987, 92: 14739-14760 [doi]

10 Araguás-Araguás L, Klaus F, Rozanski K. Stable isotope composition of precipitation over southeast Asia. J Geophys Res, 1998, 103: $28721-28742 \underline{\text { [doi] }}$

11 Tian L D, Masson-Delmotte V, Stievenard M, et al. Tibetan Plateau summer monsoon northward extent revealed by measurements of water stable isotopes. J Geophys Res, 2001, 106: 28081-28088[doi]

12 Tian L D, Yao T D, Schuster P F, et al. Oxygen-18 concentrations in recent precipitation and ice cores on the Tibetan Plateau. J Geophys Res, 2003, 108: 4293, [doi]

13 Zhang X P, Masayoshi Nakawo, Yao T D, et al. Variations of stable isotopic compositions in precipitation on the Tibetan Plateau and its adjacent regions. Sci China Ser D-Earth Sci, 2002, 45: 481-493[doi]

$14 \mathrm{Yu}$ W S, Yao T D, Tian L D, et al. Relationships between $\delta^{18} \mathrm{O}$ in precipitation and air temperature and moisture origin on a south-north transect of the Tibetan Plateau. Atmos Res, 2008, 87: 158-169 [doi]

$15 \mathrm{Yu} \mathrm{W} \mathrm{S}$, Yao T D, Tian L D, et al. Relationships of $\delta^{18} \mathrm{O}$ in summer precipitation and temperature and moisture trajectories at Muztagata, western China. Sci China Ser D-Earth Sci, 2006, 49: 27-35[doi]

16 Yao T D, Thompson L G, Jiao K Q, et al. Recent warming as recorded in the Qinghai-Tibetan cryosphere. Ann Glaciol, 1995, 21: 196200

17 章新平, 施雅风, 姚檀栋. 青藏高原东北部降水中 $\delta^{18} \mathrm{O}$ 的变化特征. 中国科学 $\mathrm{B}$ 辑: 1995, 25: 540-547

18 Yao T D, Masson V, Jouzel J, et al. Relationships between $\delta^{18} \mathrm{O}$ in precipitation and surface air temperature in the Urumqi River Basin, east Tianshan Mountain, China. Geophys Res Lett, 1999, 26: 3473-3476 [doi]

19 Yu W S, Yao T D, Tian L D, et al. Oxygen-18 isotopes in precipitation on the eastern Tibetan Plateau. Ann Glaciol, 2006, 43: 263268 [doi]

$20 \mathrm{Yu} \mathrm{W} \mathrm{S,} \mathrm{Yao} \mathrm{T} \mathrm{D,} \mathrm{Tian} \mathrm{L} \mathrm{D,} \mathrm{et} \mathrm{al.} \mathrm{Stable} \mathrm{isotope} \mathrm{variations} \mathrm{in} \mathrm{precipitation} \mathrm{and} \mathrm{moisture} \mathrm{trajectories} \mathrm{on} \mathrm{the} \mathrm{western} \mathrm{Tibetan} \mathrm{Plateau.} \mathrm{Arct}$ Antarct Alp Res, 2007, 39: 688-693[doi]

21 中国科学院青藏高原综合科学考察队. 西藏气候. 北京: 科学出版社, 1984. 127

22 Rasmusson E M. Atmospheric water vapor transport and the water balance of North America: Part 1. Characteristics of the water vapor flux field. Mon Weather Rev, 1967, 95: 403-426[doi]

23 Tian L D, Yao T D, MacClune K, et al. Stable isotopic variations in West China: A consideration of moisture sources. J Geophys Res, 2007, 112: D10112, [doi]

24 姚檀栋, 丁良福, 蒲建辰, 等. 青藏高原唐古拉山地区降雪中 $\delta^{18} \mathrm{O}$ 特征及其与水汽来源的关系. 科学通报, 1991, 36: 1570一 1573

25 王宁练. 青藏高原南部和北部暖季气温年代际变化差异的界线位置. 第四纪研究, 2006, 26: 165一-172

26 田立德, 姚檀栋, Numagti A, 等. 青藏高原南部季风降水中稳定同位素波动与水汽输送过程有关. 中国科学 D辑: 地球科学, 2001, 31(增刊): 214-220

27 Rozanski K, Araguds-Araguds L, Gonfiantini R. Isotopic patterns in modem global precipitation. In: Swart P K, Lohman K C, McKenzie J, et al, eds. Climate Change in Continental Isotopic Records: Geophysical Monograph 78. Washington D C: American Geophysical Union, 1993. 1-36

28 李国平，段廷扬，巩远发。青藏高原西部地区的总体输送系数和地面通量. 科学通报, 2000, 45: 865-869 